\title{
Radioisotope electric propulsion (REP): A near-term approach to nuclear propulsion
}

\author{
George R. Schmidtt,*， David H. Manzella ${ }^{a}$, Hani Kamhawia ，Tibor Kremic ${ }^{a}$ ，Steven R. Oleson ${ }^{a}$, \\ John W. Dankanich ${ }^{b}$, Leonard A. Dudzinskic
}

a NASA Glenn Research Center, Cleveland, Ohio, USA

${ }^{\mathrm{b}}$ Gray Research, Cleveland, Ohio, USA

'NASA Headquarters, Washington, DC, USA

\section{A R T I C L E I N F O}

\section{Article history:}

Received 31 January 2009

Received in revised form

19 June 2009

Accepted 11 July 2009

Available online 5 August 2009

\section{Keywords:}

Propulsion

Nuclear power

Electric propulsion

Nuclear electric propulsion

Radioisotope power

Radioisotope electric propulsion REP

NEP

\begin{abstract}
A B S T R A C T
Studies over the last decade have shown radioisotope-based nuclear electric propulsion to be enhancing and, in some cases, enabling for many potential robotic science missions. Also known as radioisotope electric propulsion (REP), the technology offers the performance advantages of traditional reactor-powered electric propulsion (i.e., high specific impulse propulsion at large distances from the Sun), but with much smaller, affordable spacecraft. Future use of REP requires development of radioisotope power sources with system specific powers well above that of current systems. The US Department of Energy and NASA have developed an advanced Stirling radioisotope generator (ASRG) engineering unit, which was subjected to rigorous flight qualification-level tests in 2008, and began extended lifetime testing later that year. This advancement, along with recent work on small ion thrusters and life extension technology for Hall thrusters, could enable missions using REP sometime during the next decade.
\end{abstract}

Published by Elsevier Ltd.

\section{Introduction}

Nuclear electric propulsion (NEP) has been studied since the early 1960 s because of its potential for future

\footnotetext{
Abbreviations: ASC, advanced Stirling converter; AU, astronomical unit; ASRG, advanced Stirling radioisotope generator; DOE, US Department of Energy; EU, engineering unit; GPHS, general purpose heat source; Isp, specific impulse; JIMO, Jupiter icy Moons orbiter; MMRTG, multi-mission radioisotope thermoelectric generator; NEP, nuclear electric propulsion (reactor-powered electric propulsion); PPU, power processing unit; REP, radioisotope electric propulsion; RPS, radioisotope power system; RTG, radioisotope thermoelectric generator; SEP, solar electric propulsion; TRL, technology readiness level

${ }^{*}$ Corresponding author.

E-mail addresses: George.Schmidt@nasa.gov (G.R. Schmidt), David.Manzella@nasa.gov (D.H. Manzella), Hani.Kamhawi-1@nasa.gov (H. Kamhawi), Tibor.Kremic@nasa.gov (T. Kremic), Steven.R.Oleson@nasa.gov (S.R. Oleson), John.Dankanich@nasa.gov (J.W. Dankanich), Leonard.Dudzinski@nasa.gov (L.A. Dudzinski).
}

high-energy space missions. Almost all NEP assessments to date have assumed fission reactors as the nuclear energy source. Unlike solar-powered electric propulsion (SEP) systems, NEP operation is generally independent of distance and orientation with respect to the Sun.

The most recent, well-known NEP effort, NASA's Jupiter icy Moons orbiter (JIMO) mission concept evaluation, took place from 2002 to 2005 [1], and considered relatively small reactors of up to a few hundred kilowatts in power. The intent was to limit vehicle size and cost, which seemed to be a reasonable goal for first use of the technology. Unfortunately because of reactor criticality constraints, the system specific power of the JIMO spacecraft (i.e., power per unit mass) was very poor, and this limited vehicle acceleration, increased mission time, and reduced spacecraft maneuverability in Jupiter's large gravity well.

Although these limitations are partially offset by having a power rich environment at destination for science and 


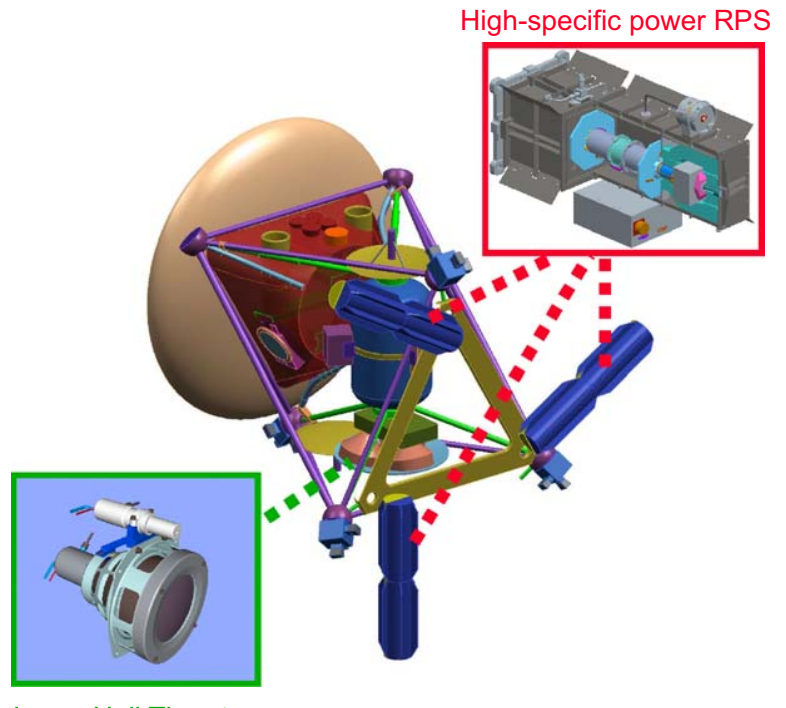

Ion or Hall Thrusters

Fig. 1. REP-based spacecraft concept.

payload operations, it is difficult to find science users with collective power requirements much more than just a few kilowatts. Vehicle acceleration for reactor-based NEP generally improves with power, especially at multi-megawatt power levels, but increasing power beyond several kilowatts offers marginal and diminishing returns for science. It also translates to larger radiators, more massive power processing equipment and larger spacecraft. There is a clear mismatch between science requirements, which favor smaller, faster spacecraft and several kilowatts of power, and reactorbased NEP, which favors large, $100-1000 \mathrm{~kW}$-scale spacecraft.

Over the last decade, several studies have pointed to radioisotope power systems (RPS), instead of reactor power sources, as the best way of implementing NEP. Radioisotopebased NEP, also known as radioisotope electric propulsion (REP), has been evaluated before, but has not been seriously considered for flight due to the low specific powers of traditional radioisotope generators, which range from 3 to $5 \mathrm{We} / \mathrm{kg}$ (watts-electric/kilogram). However, the prospects for REP have improved substantially with the advent of new higher specific-power radioisotope generators based on dynamic Stirling power conversion. The US Department of Energy (DOE) and NASA have initiated the development of an advanced Stirling radioisotope generator (ASRG), which will provide a specific power of approximately $8 \mathrm{We} / \mathrm{kg}$. When used with small ion or Hall thrusters, as in the spacecraft concept shown in Fig. 1, REP offers the specific impulse (Isp) and acceleration performance of reactor-based NEP, but with much smaller and affordable spacecraft.

In this capacity, REP would principally be used as an interplanetary stage. It would provide steady acceleration following launch to a positive Earth escape energy ( $C 3 \geq 0 \mathrm{~m}^{2} / \mathrm{s}^{2}$ ) or boost by a chemical or solar-powered electric propulsion stage. At remote destinations, REP would perform deceleration, orbit insertion and maneuvers around outer planets and other planetary bodies. REP-based spacecraft could also provide ample power at destination for sophisticated science instruments and communications, but it would fit better within the relatively modest kilowatt-scale power requirements of the space science community.

\section{Prior mission evaluations}

The earliest studies of REP were conducted by Robert Noble of Fermi National Accelerator Laboratory [2-4]. He evaluated the technology for sending small robotic spacecraft to the outer Solar System and near-interstellar space. His studies properly identified specific power of the radioisotope generator as a key parameter limiting mission performance. The bounds that he assumed for specific power, that is $5-10 \mathrm{We} / \mathrm{kg}$, reflected a reasonable range between stateof-the-art and what could be expected with advanced technology.

Noble's studies showed that REP, when augmented with chemical propulsion and gravity assist, could enable fast rendezvous missions to the outer Solar System and fast escape trajectories to near-interstellar space. Rendezvous missions to the Pluto-Charon system using chemical propulsion and REP could be conducted with 10-20 year flight times. Combined with a Jupiter gravity assist, an REP heliopause orbiter could be placed at a 100 astronomical unit (AU) parking orbit in 20-30 years. Finally, REP and a powered Jupiter gravity assist could enable a spacecraft to fly out to the first gravitational lens focus of the Sun (550 AU) in 40-50 years.

Work on REP expanded in the early 2000s, motivated by the interest in relaxing launch window constraints and reducing mission times for NASA's Pluto-Kuiper Belt mission. Steven Oleson et al. at NASA's Glenn Research Center examined various system options, including use of RPS for both spacecraft power and propulsion, and considered a number of different launch vehicles for placement into interplanetary trajectories (Table 1) [5].

Their study identified technology options that eliminated the need for a 2004 Jupiter gravity assist, but still enabled arrival at Pluto before 2020. The most promising concept involved a direct insertion into an Earth escape trajectory using a single Delta II (2925) launch vehicle. The spacecraft utilized small sub-kilowatt ion thrusters and high-specific power Stirling radioisotope generators. It could be launched on a launch vehicle smaller than the all-chemical baseline, and would allow a launch slip to 2014, while maintaining a flyby by 2020 .

Encouraged by these promising results, the same group began to examine REP for orbital missions about Uranus, Neptune, Pluto, and other outer planetary targets. The trade space was opened to propulsion concepts that enabled relatively quick missions to destinations in the outer Solar System [7]. Several options with and without REP were explored, including reactor and solar-powered electric propulsion stages combined with aerocapture. Unlike prior work that had focused on fast flybys, this study concentrated on outer planet orbiters. With medium class launch vehicles and a new direct trajectory, these sub-kilowatt ion thrusters and Stirling radioisotope generators were found to shorten mission times to 5 and 12 years for Saturn and Pluto, respectively. The study showed that in addition to outer 
Table 1

Launch vehicle performance: launch of payload to escape velocity (C3 $\left.=0 \mathrm{~m}^{2} / \mathrm{s}^{2}\right)[6]$.

\begin{tabular}{ll}
\hline Launch vehicle & Payload (kg) \\
\hline Delta II (2920) & $570-665$ \\
Delta II (2425) & $750-775$ \\
Delta II (2920 heavy) & $775-845$ \\
Delta II (2925) & $1155-1235$ \\
Delta II (2925 heavy) & $1370-1425$ \\
Atlas V (501) & 2680 \\
Delta IV (4040) & 2735 \\
Atlas V (401) & 3445 \\
Atlas V (511) & 3765 \\
Delta (4240) & 4075 \\
Atlas V (521) & 4545 \\
Delta IV (4450) & 4580 \\
Atlas V (531) & 5210 \\
Atlas V (541) & 5820 \\
Atlas V (551) & 6330 \\
Delta IV (4050 heavy) & 9305 \\
\hline
\end{tabular}

planets and their moons, the REP system could enable equally fast missions to other outer planetary objects, such as Trojan and main belt asteroids, Centaurs, TransNeptunian objects, Kuiper Belt objects, and various comets. A new direct trajectory was discovered that would enable medium-size, relatively fast planetary orbiter missions within the $\$ 700-800$ million cost cap of NASA's New Frontiers program.

In 2003, NASA's Science Mission Directorate initiated a study to assess REP for specific New Frontier class missions [8]. REP was compared against state of the art chemical and solar electric propulsion concepts. The three science missions included a Trojan Asteroid Orbiter, a Comet Surface Sample Return spacecraft, and a Jupiter Polar Orbiter with Probes. The results showed that REP offers a significant trip time reduction and increased target capture for the Trojan Asteroid Orbiter mission when utilizing an advanced 2ndgeneration RPS and an advanced Hall thruster. (Marginal benefits were realized with the use of current 1st-generation RPS.) REP was not well suited for the Jupiter mission primarily due to the increased propellant mass required for capturing into a final parking orbit. For the Comet mission, REP appeared to be the superior option, although the authors noted that more analyses should be performed. Overall, REP appeared to be the best technology for small body missions beyond the main asteroid belt.

Subsequent studies evaluated use of REP with SEP and other propulsion technologies to reduce mission times [9]. A Neptune Orbiter mission was evaluated assuming use of SEP, REP, chemical propulsion, and combinations thereof. An example was the SEP/REP combination, where SEP was used for acceleration to the orbit of Mars, followed by REP for further acceleration and deceleration into Neptune orbit. REP also improved the maneuverability and power capabilities of the spacecraft about the target body, which was very limited with a chemically propelled spacecraft. Results showed that, compared to the SEP/aerocapture scenario, REP in conjunction with chemical propulsion for planetary capture can replace the aerocapture system, but with a trip time penalty. Eliminating the combined SEP stage/aerocapture system, and utilizing a slightly larger launch vehicle, Star 48 upper stage, and a combined $\mathrm{REP} /$ chemical capture system, the trip time can nearly be matched, while providing over a kilowatt for science at destination following the REP maneuver. The REP/chemical combination looked particularly promising. Not only does it deliver the spacecraft to Neptune with comparable trip times to the SEP/aerocapture option, but it also provides a spacecraft with more power and a fully functional electric propulsion system at destination.

The potential benefits of REP spurred more studies to show how REP could effectively complement SEP for missions to distant targets with modest payload requirements. Williams et al. [10] investigated the application of an advanced REP for a sample/return mission to the Comet Tempel 1. A set of mission and system parameters were varied with the goal of quantifying their impact on total mission payload. Mission parameters considered included trip-time and Earth reentry speed of the sample-return system. System parameters considered included launch vehicle (Table 1), spacecraft power level, and thruster Isp. For the baseline case of an Atlas V (401) and REP power level of $750 \mathrm{~W}$, the mission time was 12 years, the payload was $144 \mathrm{~kg}$, and the missions optimized to a Isp value well within Hall thruster range. Other cases included the larger Atlas V (551) launch vehicle and extended power level up to $1 \mathrm{~kW}$. A power level of at least $1 \mathrm{~kW}$ and trip-time of approximately 11 years was required to obtain a total science payload close to $320 \mathrm{~kg}$ for the Atlas V (401) launch vehicle. An Atlas V (551) launch vehicle yielded a science payload of approximately $540 \mathrm{~kg}$ for the case of $1 \mathrm{~kW}$ of power and an 11-year trip time, and nearly $250 \mathrm{~kg}$ of science payload for the case of $1 \mathrm{~kW}$ of power and a 6-year trip time.

In 2006, Fiehler and McNutt continued along the lines of Noble 10 years earlier and performed a study of an Innovative Interstellar Explorer mission under a NASA Vision Mission study [11]. The goal of this mission concept was to send a probe to a heliospheric distance of $200 \mathrm{AU}$ in a reasonable amount of time. Previous studies had looked at using a near-Sun propulsive maneuver, solar sails, and fission reactor-powered electric propulsion systems for propulsion. The Innovative Interstellar Explorer's mission design used a combination of a high-energy launch using current launch vehicles, a Jupiter gravity assist, and REP. Many direct and gravity-assist trajectories at several power levels were considered in the development of the baseline trajectory, including single and double-gravity assists utilizing the outer planets. A detailed spacecraft design study was completed followed by trajectory analyses to examine the performance of the spacecraft design options.

International interest in REP has appeared with a recent study by Casaregola et al. [12]. They considered use of a radioisotope thermoelectric generator (RTG) with electric propulsion to provide main propulsion functions during the transfer phase of deep space missions. A parametric study was performed that looked at different power and propulsion characteristics for a possible future mission to the outer planets. Three different transfer strategies were evaluated, including one case with a complete planetary capture. With the inclusion of a capture, the transfer feasibility depends even more on launcher performance for a given spacecraft mass. The advantages and disadvantages of such strategies within the envelope of defined control parameters and 
constraints were addressed for different destination planets and transfer strategies. Overall, the study demonstrated the feasibility of an RTG-based REP strategy for outer planetary missions.

All of the REP studies to date have pointed to the increasing benefit of using advanced, high-specific power RPS. A system specific power of at least $8 \mathrm{We} / \mathrm{kg}$ is necessary for most applications. Chapman et al. took this approach one step further and began examining how a high-specific power, 2nd-generation RPS could be designed to provide more performance advantages for an REP mission [13]. They studied two different spacecraft power and propulsion system architectures to support a mission to the Martian Moons, Phobos and Deimos. The first utilized existing or soon to be available components, that is the multi-mission RTG (MMRTG), the NSTAR ion thruster and power processing unit (PPU). The second was based on a 2nd-generation Stirling generator operating with a vector-controlled multiconvertor Stirling power conversion system to achieve significant improvement in specific power and system efficiency. This approach eliminated the need for traditional $\mathrm{ac} / \mathrm{dc}$ electric power conversion and enabled provision of the required $1000-2000$ Vdc bus power directly from the generator. This resulted in much higher efficiency, lower PPU mass, and lower heat rejection system mass. The study illustrated the significant improvements in system performance with the 2nd-generation approach compared to existing technology.

In summary, REP appears to be best suited for robotic exploration of moons and small planetary bodies. Its use is enhanced by application of small lightweight spacecraft structures, and enabled by the development of high-specific power RPS. Mission times with REP are comparable to and, in some cases, shorter than with other technologies. However, overall trip times could be lowered dramatically by using larger launch vehicles and inserting spacecraft into more energetic earth escape trajectories. Prior studies have primarily considered the launch vehicle options shown in Table 1 , but new heavy lift vehicles that may be available next decade, such as the US Ares V, could enable larger REP spacecraft and even shorter mission times.

\section{System description}

Apart from being approximately 10 times smaller in thrust and power than SEP, a typical REP system would operate generally the same as an SEP stage. Most prior studies have assumed spacecraft power levels below $1 \mathrm{~kW}$, but this has been due to the emphasis on small spacecraft. From a technology perspective, there is no reason why larger spacecraft in the multi-kilowatt range could not be considered. Spacecraft power levels are practically limited by cost and radioisotope fuel availability.

The three key technologies needed for an REP spacecraft are sub-kilowatt-class electric thrusters capable of at least several thousand seconds of Isp, lightweight structures and payload systems, and advanced, high specific power RPS. None of these are technology show-stoppers, but they will require flight hardware development and qualification before reaching a stage of mission readiness.
Perhaps the greatest challenge facing use of REP now is the limited supply of the Plutonium fuel (Pu-238) used in all the RPS that have flown in space to date. Another challenge is the high cost of RPS due to its expensive fuel and more stringent environmental and safety requirements.

\section{Thrusters}

Most prior REP studies have assumed the use of ion thrusters with power levels less than $1 \mathrm{~kW}$. The main challenge here is developing a flight qualified thruster that could operate continuously at sub-kilowatt power levels for many years in deep space. Although such a thruster does not currently exist, recent work on these types of systems, along with thrusters designed for higher power levels, would make such a development relatively straightforward.

Up until the early 2000s, NASA Glenn had a project underway to develop a lightweight sub-kilowatt ion thruster and PPU. The thruster design was tailored to the meet the needs of the satellite and spacecraft integration community, as identified in an extensive user survey performed by General Dynamics. The basic characteristics of the system were: $\leq 20 \mathrm{mN}$ thrust; $100-500$ We input power; $1600-3500 \mathrm{~s}$ Isp; $0.95 \mathrm{~kg}$ thruster mass; $2.0 \mathrm{~kg}$ PPU mass; and $3.1 \mathrm{~kg}$ central xenon feed system mass (excluding tank). The combined thruster and PPU mass of $<3.0 \mathrm{~kg}$ represented a $80 \%$ reduction over state-of-the-art at that time. The thruster, which is shown in Fig. 2, had performance goals of 50\% efficiency at $0.25 \mathrm{~kW}$, which represented a two-fold increase over stateof-the-art.

The sub-kilowatt ion propulsion activity included both an in-house hardware development element for the thruster and power processor, as well as a contracted system element [14]. At NASA Glenn, the fabrication and performance assessment of a small $(0.25 \mathrm{~kW}$ class) laboratory model thruster with an 8-cm beam diameter was completed in 1998. Fabrication of a 2nd-generation lightweight engineering model thruster with a $100-500 \mathrm{~W}$ power throttling envelope was also performed. First- and second-generation breadboard power processors were also fabricated and successfully integrated with the 8-cm thruster [15]. General Dynamics, under

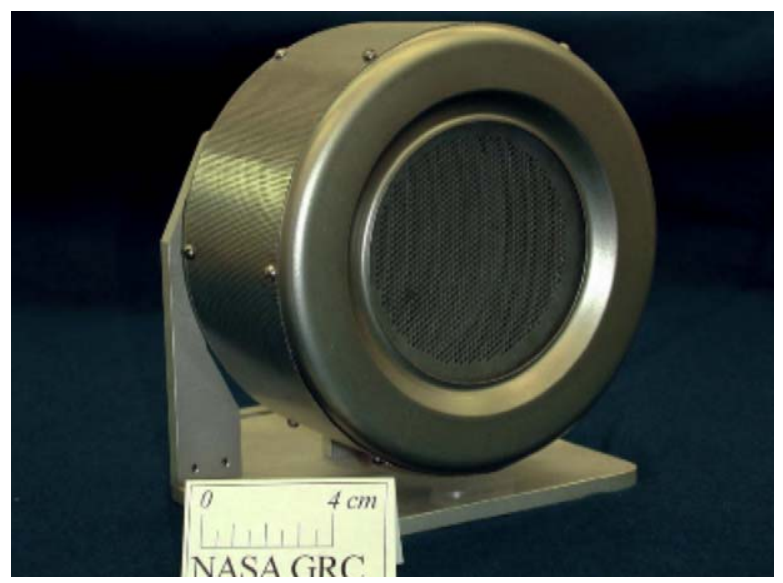

Fig. 2. NASA 8-cm ion thruster. 


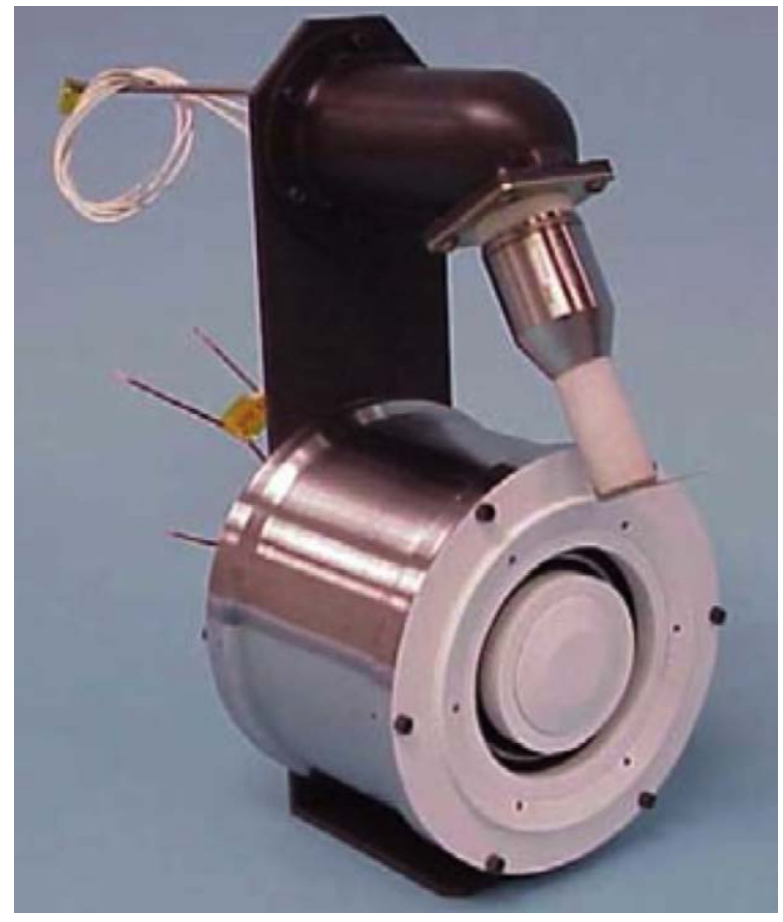

Fig. 3. Busek BHT-600 single outer coil thruster.

contract, developed a conceptual design for the ion propulsion system. The objectives of this effort were to develop a system that improved performance and reduced system mass compared to existing systems.

Another form of electric propulsion that may be applicable to an REP system is the Hall thruster. Commercial Hall thrusters exist today that fit the general power level and many of the performance requirements needed by small REP spacecraft. One is the Busek sub-kilowatt thruster, shown in Fig. 3.

Despite the maturity of some of these Hall thrusters, they have been considered in only a few REP studies because of their limited lifetime $(\sim 2000 \mathrm{~h})$, arising from erosion of the thruster's insulating channel. However, if the lifetime limitation could be overcome, then Hall thrusters would be an excellent choice for REP missions due to their comparatively lower cost. This would be consistent with the investment expected for New Frontiers or Discovery-class spacecraft.

NASA Glenn is currently developing a technology that could greatly increase the operational lifetimes and Isp of Hall thrusters. Although this innovation is being conducted to meet NASA's requirements for SEP applications, the technology is viable for long-duration REP missions. This technology breakthrough has already been verified through wear testing of the $3.5 \mathrm{~kW}$ laboratory Hall thruster-designated as the NASA-103 M.XL-for more than $4700 \mathrm{~h}$ with a demonstrated Isp of up to $2800 \mathrm{~s}$. This thruster, shown in Fig. 4, is projected to have an operational throughput capability of $>300 \mathrm{~kg}$ of xenon [16].

The NASA-103 M.XL thruster incorporates innovative new technology that eliminates the lifetime limitation for

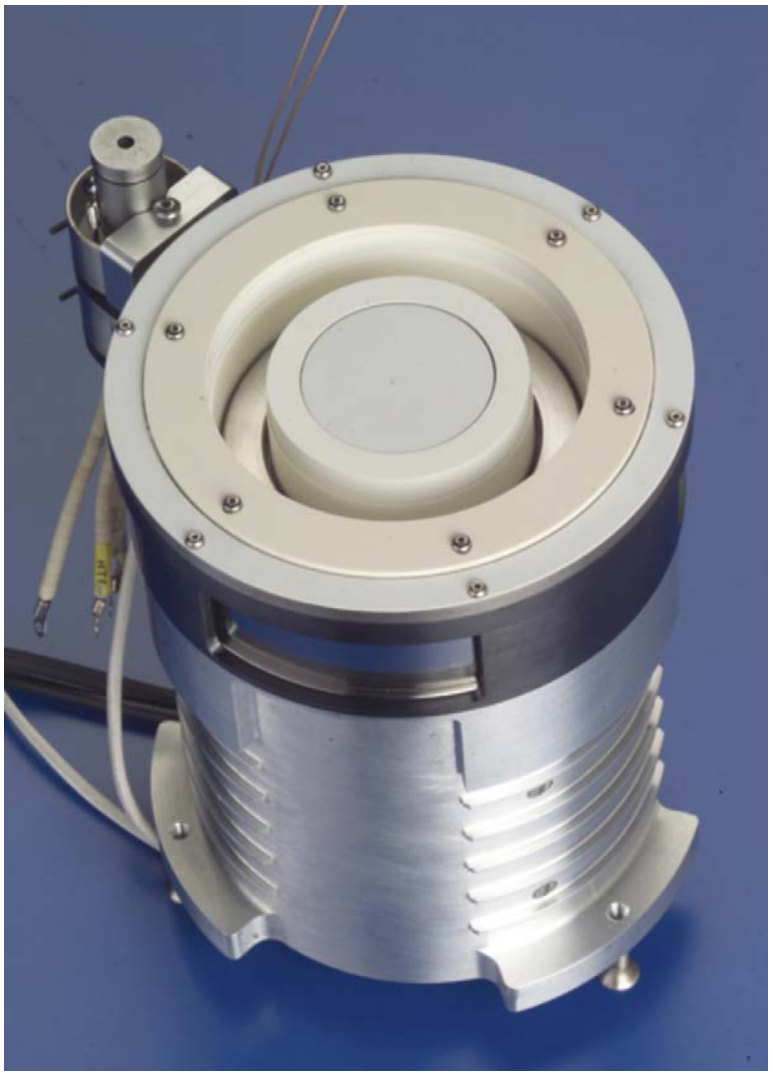

Fig. 4. NASA-103 M.XL Hall thruster.

Hall thrusters associated with erosion of the downstream edge of the discharge channel by sputtering. Furthermore, by eliminating the lifetime limitations associated with discharge channel erosion, this technology allows Hall thrusters to perform long duration missions at considerably higher Isp than previously possible.

Although the innovations incorporated into the NASA103 M.XL extend the lifetime capability of this Hall thruster sufficiently to enable continuous multi-year operation, the thruster operates at powers 3-4 times what would be needed for REP missions. However, it is conceivable that an existing thruster could be modified with this life-extending mechanism and then re-qualified for flight. To this end, NASA Glenn and Busek are jointly incorporating this feature into Busek's BHT-600 thruster under the auspices of NASA's Innovative Partnership Program. This effort will improve the prospects of using Hall thrusters for future REP applications.

\section{Lightweight spacecraft buses and systems}

Another technology that is enabling to REP, at least for small $<1-\mathrm{kW}$ concepts, is lightweight structures and payloads. This will be particularly important for near-term applications involving small but capable spacecraft. Studies by Oleson et al. identified $100-120 \mathrm{~kg}$ as a reasonable goal. This estimate includes all mass other than propulsion and power, and does include the payload and science instruments [7]. 


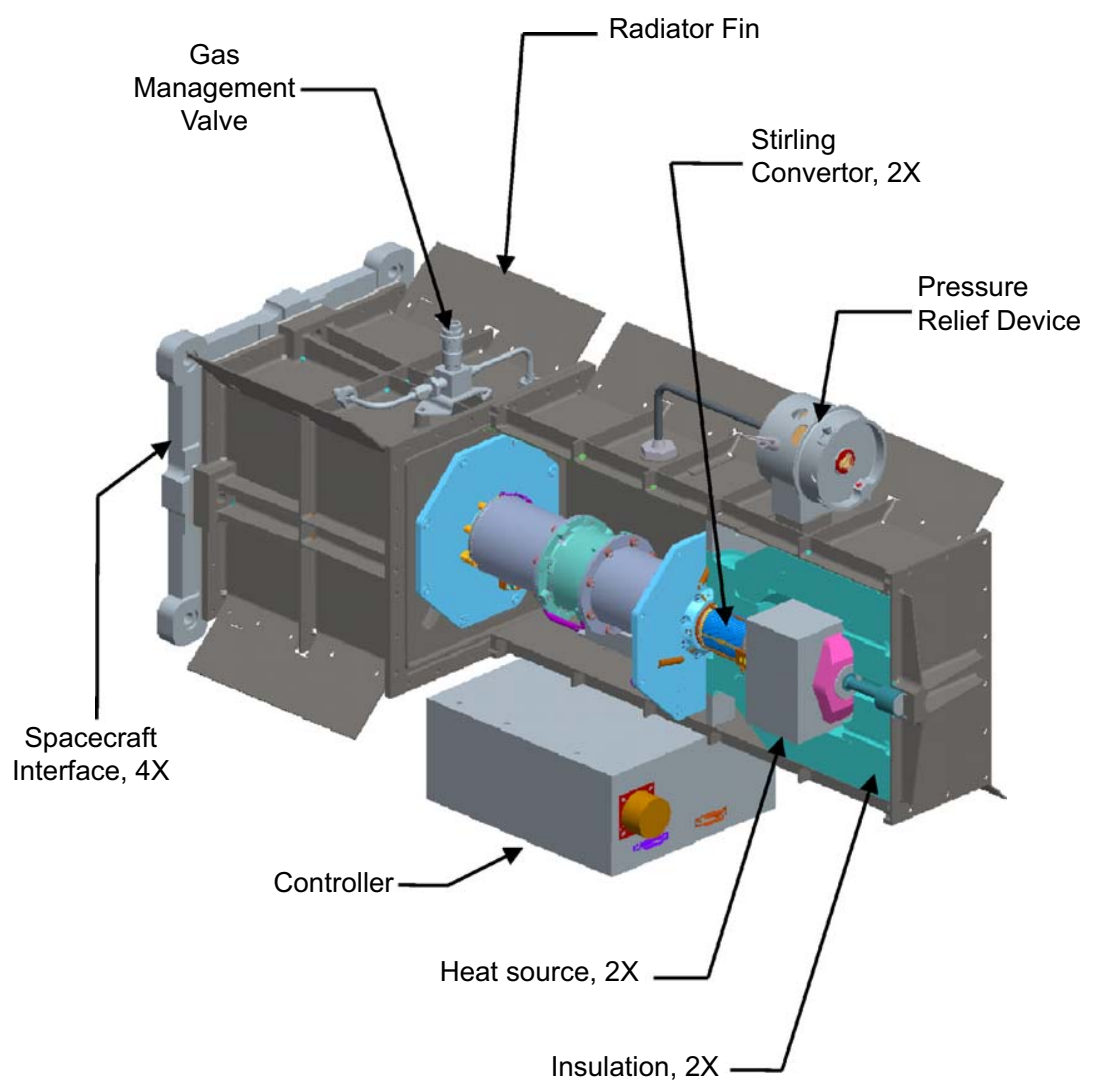

Fig. 5. Advanced Stirling radioisotope generator (ASRG).

The Johns Hopkins University Applied Physics Laboratory has built several interplanetary spacecraft of this class, including NEAR, Contour and Messenger. Advanced microelectronics/lightweight spacecraft bus development has been underway at the Applied Physics Laboratory and will be leveraged toward outer planet mission opportunities.

Two strategies that help reduce the science instrument package mass are instrument integration and spacecraftdirected instrument pointing. These factors make a $100-120 \mathrm{~kg}$ class spacecraft for deep space possible.

\section{Advanced radioisotope power}

When REP was first investigated, the principal challenge appeared to be development of an advanced RPS with a high specific power ( $\geq 8 \mathrm{We} / \mathrm{kg}$ ). This is a significant advancement over the general purpose heat source (GPHS)-RTG used on all RPS-powered missions since $1989(\sim 5.2 \mathrm{We} / \mathrm{kg})$ and the MMRTG currently under development for the Mars Science Laboratory (MSL) mission ( $\leq 3 \mathrm{We} / \mathrm{kg}$ ). Recently, NASA decided to proceed with development of the ASRG engineering unit (EU), an advanced RPS prototype, shown in Fig. 5 [17].

This unit will enable the most exciting mission opportunities offered by REP, in addition to providing significant mass improvements for all RPS-based missions. In fact, the
ASRG is being designed for multi-mission use in environments with and without atmospheres for both deep space and the Mars atmosphere.

In addition to high specific power, the ASRG employs a dynamic Stirling conversion cycle with an efficiency of over $30 \%$. This is $4-5$ times higher than current thermoelectric generators, and is particularly important for conserving the very limited supply of Pu-238 fuel.

The ASRG is being developed under the joint sponsorship of DOE and NASA. The prime contractor is LockheedMartin Corporation of Valley Forge, PA, with Sunpower, Inc. of Athens, Ohio, as the main subcontractor. NASA Glenn is supporting the technology development along with evaluation and testing of the Stirling convertors used in the device [18].

Activities are currently focused on developing the ASRG engineering unit (EU), which is shown in Fig. 6. The ASRG-EU uses two opposed advanced Stirling convertors (ASCs), operating at a hot-end temperature of $650^{\circ} \mathrm{C}$, and is expected to produce about 140 We of power. Sunpower is developing the ASC under a NASA Research Announcement with NASA Glenn. The low mass of the ASC is key to the ASRG's high overall system specific power. With a specific power of $90 \mathrm{We} / \mathrm{kg}$, the ASC represents a six-fold improvement in mass over today's thermoelectric generators. These convertors have been provided to Lockheed-Martin as governmentfurnished equipment. 


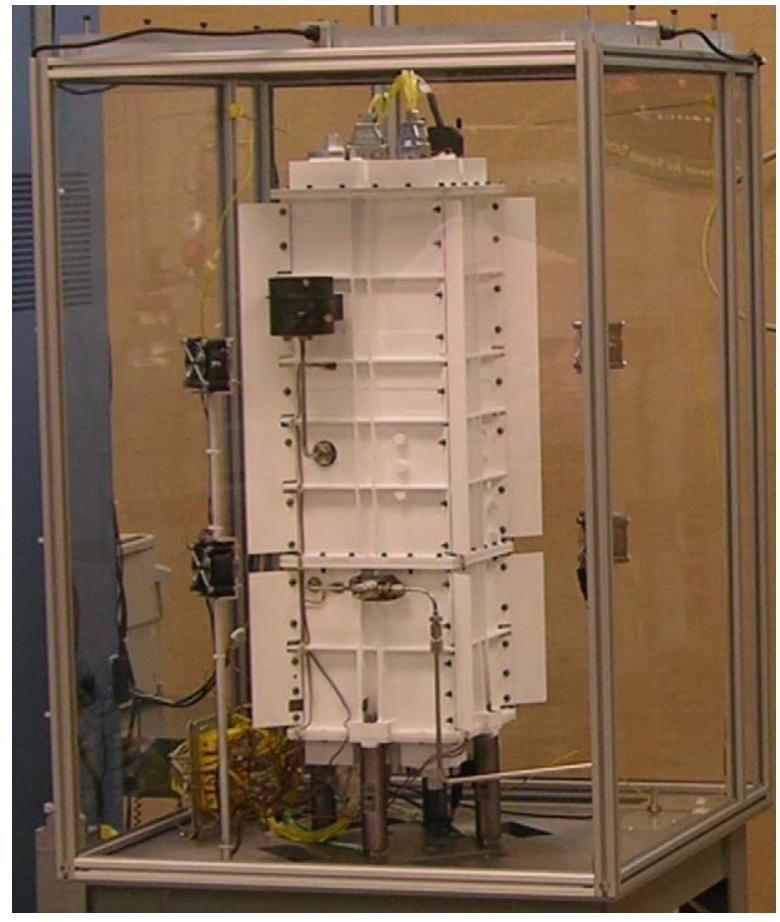

Fig. 6. ASRG engineering unit.

Sunpower and NASA Glenn are also developing a highertemperature ASC with a MarM-247 alloy heater head. That converter will be capable of operating up to an $850^{\circ} \mathrm{C}$ hotend temperature. This has the potential to increase the ASRG specific power to $\sim 8.4 \mathrm{We} / \mathrm{kg}$ and provides increased margin with the MarM-247 material at $850^{\circ} \mathrm{C}$ compared to the Inconel 718 material, currently used on the ASRG-EU, at $650^{\circ} \mathrm{C}$.

The ASRG is on track to achieve a technology readiness level (TRL) of 6 (i.e., system demonstration in a relevant environment) by the end of 2009. Continuous, non-stop testing of the ASCs was initiated on January 2007, and these units have operated without any performance degradation since that time. These ASCs were shipped to Lockheed-Martin in October 2007, where they have been integrated into the ASRG-EU. Initial system-level testing of the ASRG-EU was initiated in early 2008, which was followed by extended duration testing at NASA Glenn starting in the fall of 2008.

These tests use electrical resistance heaters that simulate the heating characteristics of the actual GPHS module. Avoiding use of nuclear materials during early phases of development greatly facilitates testing and evaluation of the ASRG subsystems.

\section{Conclusions}

Various authors have studied and evaluated the use of REP for science missions beyonds Earth orbit. More recent work has shown that such spacecraft can orbit or co-orbit various large and small science targets with transit times comparable to large reactor-based NEP vehicles, but with the more reasonable power levels needed for science instruments and payloads. Although REP vehicles would be much smaller and have less on-board power available for science instruments than reactor-based NEP, REP vehicles, like those using traditional NEP, could conduct missions that are difficult or impossible to do with chemical, solar electric or aerocapture vehicles.

REP has been limited to studies, because until recently there were no plans for development of a radioisotope power source with the system specific powers required to make REP feasible. With NASA moving toward a TRL 6 demonstration of the ASRG-EU by the end of 2009, the prospects for REP appear to be excellent. A flight-qualified ASRG would likely offer specific masses of $\geq 8 \mathrm{We} / \mathrm{kg}$, and could be ready for flight by 2013-2014. This opens the door for carrying out one or two REP missions sometime during the next decade, assuming the parallel development of an electric propulsion system sized for the appropriate power levels.

\section{References}

[1] S.R. Oleson, Electric propulsion technology development for the Jupiter icy Moons orbiter project, in: Joint Propulsion Conference, AIAA-2004-3449, July 2004.

[2] R.J. Noble, Radioisotope electric propulsion of small payloads for regular access to deep space, in: Joint Propulsion Conference, AIAA1993-1897, July 1993.

[3] R.J. Noble, Radioisotope electric propulsion for robotic science missions to near-interstellar. Space, Journal of British Interplanetary Society 49 (1996) 322-328.

[4] R.J. Noble, Radioisotope electric propulsion for small robotic space probes, Journal of British Interplanetary Society 49 (1996) 455-468.

[5] S. Oleson, L. Gefert, M. Patterson, J. Schreiber, S. Benson, J. McAdams, P. Ostdiek, Outer planet exploration with advanced radioisotope electric propulsion, in: International Electric Propulsion Conference, IEPC-01179, 2001.

[6] 〈 http://elvperf.ksc.nasa.gov/elvMap/staticPages/launch_vehicle_ info1.html,, NASA Launch Services Program Website, Performance Query Tool.

[7] S. Oleson, S. Benson, L. Gefert, M. Patterson, J. Schreiber, Radioisotope electric propulsion for fast outer planetary orbiters, in: Joint Propulsion Conference, AIAA-2002-3967, July 2002.

[8] D. Oh, E. Bonfiglio, M. Cupples, J. Belcher, K. Witzberger, D. Fiehler, G. Artis, Evaluation of radioisotope electric propulsion for selected interplanetary science missions, in: International Electric Propulsion Conference, IEPC-2005-181, 2005.

[9] D. Fiehler, S. Oleson, Neptune orbiters utilizing solar and radioisotope electric propulsion, in: Joint Propulsion Conference, AIAA-2004-3978, 2004.

[10] R. Williams, Y. Gao, C. Kluever, Interplanetary sample return missions using radioisotope electric propulsion, in: Joint Propulsion Conference, AIAA-2005-4273, 2005.

[11] D. Fiehler, R. McNutt, Mission design for the innovative interstellar explorer vision mission, Journal of Spacecraft and Rockets 43 (6) (2006).

[12] C. Casaregola, K. GEUrts, P. Pergola, M. Andrenucci, Radioisotope lowpower electric propulsion missions to the outer planets, in: Joint Propulsion Conference, AIAA-2007-5234, 2007.

[13] J. Chapman, R. Cassady, J. Fisher, A. Kristalinski, Vector controlled Stirling based power conversion approach for radioisotope powered missions, in: International Energy Conversion Engineering Conference, AIAA-2003-6038, 2003.

[14] M.J. Patterson, Low-power ion thruster development status, in: Joint Propulsion Conference, AIAA-1998-3347, 1998.

[15] L.R. Pinero, G.E. Bowers, Sub- kilowatt power processing unit with an 8-cm ion thruster, in: International Electric Propulsion Conference, IEPC-01-331, 2001.

[16] D. Manzella, Low cost electric propulsion for deep space robotic missions, in: 2007 NASA Science Technology Conference, D10P2, June 2007.

[17] R. Richardson, J. Chan, Advanced Stirling radioisotope generator development, in: 2007 NASA Science Technology Conference, D2P2, June 2007.

[18] R. Shaltens, W. Wong, Advanced Stirling technology development, in: 2007 NASA Science Technology Conference, D2P1, June 2007. 